\title{
Amibas de vida libre en pozas, piscinas y lagos de El Salvador
}

\author{
Marta Esperanza Castillo de Mena ${ }^{1}$ \\ René Guillermo Santos Herrera ${ }^{2}$ \\ Mirna Maricely Cerna de López ${ }^{3}$ \\ Elia Gicela Torres de Castillo ${ }^{4}$ \\ Alexandra Manoela Portillo de Juarez ${ }^{5}$ \\ Rogelio Isaac Rosales Quintanilla ${ }^{6}$
}

\section{RESUMEN}

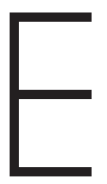

n este trabajo se examinaron 60 muestras de agua provenientes de 30 sitios del territorio salvadoreño donde se ubican reservorios de agua utilizados por la población para su diversión. La identificación de cada muestra incluyó: fecha de colecta, ubicación del lugar, toma de superficie o profundidad, y condición clorada o no clorada. Se sedimentó cada muestra y éste se estudió entre lámina y laminilla, utilizando objetivos 10X y 40X del microscopio, en busca de formas móviles de amibas. Adicionalmente, del sedimento se sembraron cuatro placas de agar-agar sembradas con Escherichia coli vivas o muertas. Los cultivos se examinaron utilizando objetivo $4 \mathrm{X}$ del microscopio. De las colonias se realizaron preparaciones al fresco y se observaron al microscopio con objetivos de 10X y 40X. A las preparaciones que mostraron trofozoitos de amibas se les fijó con
PVA (alcohol poli vinílico) y les tiñó con coloración tricrómica. Se consideraron AVL (amibas de vida libre) los trofozoitos que presentaron dos o más de estas características: tamaño de 13 a 30 micrómetros, seudópodos redondeados, y núcleo con un cariosoma prominente rodeado por un halo claro. Se encontraron AVL en dos muestras de agua tomadas del fondo de piscinas con agua clorada, y en una muestra tomada del fondo de otra piscina de agua no clorada.

Palabras clave: Amibas de vida libre (AVL), reservorios de agua, piscinas cloradas, pozas naturales, piscinas no cloradas, El Salvador.

\footnotetext{
Licenciada en Laboratorio Clínico. Universidad de El Salvador. 1982; Master en Administración y Docencia Universitaria. Universidad Evangélica de El Salvador.1992. Comentarios: martamena4@gmail.com

Doctor en Medicina. Universidad Evangélica de El Salvador. 2003; Master en Docencia Universitaria. Universidad Evangélica de El Salvador.2007.

Licenciada en Laboratorio Clínico. Universidad de El Salvador.1985.

Doctor en Medicina. Universidad Evangélica de El Salvador.2004; Master en Docencia Universitaria. Universidad Evangélica de El Salvador.2010.

Doctor en Medicina. Universidad Evangélica de El Salvador.2004; Master en Parasitología. Instituto Pedro Kouri. Habana Cuba.2007; Master en Docencia Universitaria. Universidad Evangélica de El Salvador.

6 Doctor en Medicina. Universidad de El Salvador.2007.
} 


\section{ARTÍCULOS ORIGINALES}

\section{INTRODUCCIÓN}

Existen AVL (amibas de vida libre) que son protozoos del grupo Rhizopodos del orden amoebida (Acanthamoeba) y del orden Schizopyrenida (Naegleria y Balamuthia) que viven en la naturaleza ${ }^{1}$ y están distribuidos mundialmente en diferentes reservorios de agua como pozas ${ }^{2,3}$, piscinas, estanques, ríos, aguas salobres, aire ${ }^{4}$ etc.

Estas AVL, son llamadas anfizoicas, porque son capaces de vivir en la naturaleza y actuar como parásitos en el humano, produciendo infecciones que revisten mucha seriedad. Beltrán de Estrada ${ }^{2}$ hace mención que Fowler y Carter en 1965 fueron los primeros en descubrir la patogenicidad de las amibas de vida libre, al describir una infección fatal de meningoencefalitis por Naegleria fowleri en un australiano ${ }^{5}$ En el año de 1974 se han descrito casos de queratitis con úlcera corneal en pacientes que usan lentes de contacto'. En año 2001 se reportó un caso de infección cerebral por género Sappinia ${ }^{4}$.

Las AVL pueden atacar el sistema nervioso central produciendo meningoencefalitis amibiana primaria (MAP) por el género Naegleria; encefalitis granulomatosa amibiana (ECA) por los géneros Acanthamoeba, Balamuthia y Sappinia; además, a Acanthamoeba y Balamuthia se les ha relacionado con lesiones oculares como queratitis y úlceras cornéales, así como lesiones primarias de la piel ${ }^{3,4}$.

El género Naegleria produce cuadros de encefalitis, con elevada mortalidad en personas jóvenes con antecedentes de zambullirse en piscinas o en aguas temperadas, lo que provoca la entrada de las AVL a través de la lámina cribosa del etmoides ${ }^{7,8}$, El género Acanthamoeba afecta principalmente a pacientes inmunocomprometidos y puede provocar meningoencefalitis granulomatosa, precedida de manifestaciones respiratorias sin estar expuesto a aguas contaminadas 9,10 .
Los casos de pacientes con problemas de meningoencefalitis y queratitis están distribuidos por todo el mundo. Muchos de estos casos han tenido en común haber nadado en pozas, piscinas u otro reservorio de agua templada $2,1,11,12,7$, de ahí la importancia de determinar si esos reservorios de agua en El Salvador, están contaminados con éste tipo de amibas de vida libre.

En El Salvador existen todas las condiciones epidemiológicas necesarias para que se desarrollen estos tipos de $A \bigvee L^{2,1,13,14}$, además ha habido poca difusión de estas patologías de etiología amibiana y cuando ocurren casos, como los antes mencionados, no se piensa que pueden ser causados por estos microorganismos, dificultando el diagnóstico y, por lo tanto, el tratamiento oportuno ${ }^{1}$. Esta situación de poco conocimiento dio origen a la inquietud de realizar este estudio, de carácter exploratorio, con el único objetivo de determinar si hay presencia de AVL en el agua de reservorios utilizados por la población salvadoreña para diversión y esparcimiento.

\section{METODOLOGÍA}

Las muestras de agua se colectaron de forma aleatoria y de acuerdo con el mapa de El Salvador, que ubica los diferentes lugares en que se encuentran los reservorios de agua, utilizados por la población para recreo y esparcimiento (figura No.1). Se analizaron 30 reservorios de agua, de las cuales se colectaron 60 muestras. Las muestras se colectaron en frascos de vidrio con capacidad de $1,000 \mathrm{ml}$, tapadera de rosca, previamente esterilizados. Para muestras de agua de superficie, se destapó el frasco e inmediatamente se sumergió a una profundidad aproximada de diez centímetros permitiéndole llenarse a su capacidad. Se retiró, se colocó la tapadera, sé enviñetó y se identificó indicando: fecha de la colecta, ubicación del reservorio, tipo de muestra (superficie o profundidad), agua clorada o no clorada. 
En forma similar, se colectaron las muestras de profundidad, con la diferencia que se sumergió el frasco a una profundidad aproximada de uno a dos metros $^{15}$, las muestras se llevaron al laboratorio para su estudio, dentro de la mayor brevedad que permitió la ubicación del lugar de dónde se obtuvieron las muestras.

\section{Estudio de las muestras de agua}

En todo momento se tuvo el cuidado de proteger las muestras de agua de la contaminación ambiental. Las muestras se dejaron sedimentar durante toda la noche, se decantó el sobrenadante y se conservó el sedimento. Del sedimento de cada muestra, se realizaron cuatro preparaciones directas al fresco entre lamina y laminilla y se observaron al microscopio con objetivos 10X y 40X5,16; además se inocularon cuatro gotas de sedimento en cada una de cuatro placas de agar-agar, previamente sembradas con Escherichia coli vivas o muertas. Dos placas fueron incubadas a $37^{\circ} \mathrm{C}$ y las otras dos a $42^{\circ} \mathrm{C}$. Se examinaron los cultivos cada 24 horas, bajo el microscopio de luz a un aumento de $4 \mathrm{X}$ o con una lupa estereoscópica, hasta por siete días.

En los cultivos que mostraron resultados positivos se observaron colonias de amibas, las cuales fueron purificadas pasando una colonia de ellas a una nueva placa de agar-agar, preparada como las anteriores. Este proceso se repitió hasta obtener colonias puras, lo cual se alcanzó en aproximadamente 30 dias $^{17,2,16}$.

Se realizó un lavado con solución de Pagés a la superficie de los cultivos positivos y se hizo una preparación directa al fresco de dicho lavado, la cual fue observada al microscopio con objetivos de 10X y 40X. Cuando se observaron trofozoitos de amibas en las preparaciones, se les quitaron las laminillas a las preparaciones, se les fijó con PVA (alcohol polivinilico) se les tiñó con coloración tricrómica ${ }^{6,17,2,3}$ para observar sus características morfológicas y determinar si son las típicas de las AVL.
Si el trofozoito observado presentó dos o tres de éstas características: a) tamaño de 13 a 30 micrómetros, b) seudópodos redondeados y c) núcleo con un cariosoma prominente rodeado por un halo claro, se concluyó que dicho trofozoito correspondía a uno de AVL.

\section{RESULTADOS}

Tabla 1. Presencia de AVL en pozas, piscinas y lago.

\begin{tabular}{|c|c|c|c|c|}
\hline $\begin{array}{c}\text { Reservorio } \\
\text { de Agua }\end{array}$ & $\begin{array}{l}\text { Núm. } \\
\text { muestras } \\
\text { tomadas }\end{array}$ & $\begin{array}{l}\text { Núm. } \\
\text { muestras } \\
\text { positivas }\end{array}$ & $\begin{array}{l}\text { Tipo de } \\
\text { muestra }\end{array}$ & $\begin{array}{c}\text { Estadio del } \\
\text { parásito }\end{array}$ \\
\hline \multirow{2}{*}{$\begin{array}{l}6 \text { Pozas } \\
\text { naturales }\end{array}$} & \multirow{2}{*}{12} & o & Superficie & -------- \\
\hline & & 0 & Fondo & ------- \\
\hline \multirow{2}{*}{$\begin{array}{l}14 \text { Piscinas } \\
\text { (cloradas) }\end{array}$} & \multirow{2}{*}{28} & 0 & Superficie & ------- \\
\hline & & 2 & Fondo & Trofozoito \\
\hline \multirow{2}{*}{$\begin{array}{l}9 \text { Piscinas } \\
\text { naturales (no } \\
\text { clorada) }\end{array}$} & \multirow{2}{*}{18} & 0 & Superficie & ------- \\
\hline & & 1 & Fondo & Trofozoito \\
\hline \multirow{2}{*}{ 1Lago } & \multirow{2}{*}{2} & 0 & Superficie & ------- \\
\hline & & 0 & fondo & ------- \\
\hline Total 30 & 60 & 3 & & \\
\hline
\end{tabular}

Tabla 2. Porcentaje de positividad a AVL en muestras de aguas provenientes de diversos reservorios.

\begin{tabular}{|c|c|c|c|}
\hline $\begin{array}{c}\text { Núm. de } \\
\text { reservorios }\end{array}$ & Nombre del reservorio & $\begin{array}{c}\text { Porcentaje } \\
\text { de reservorios } \\
\text { positivos a } \\
\text { AVL }\end{array}$ & $\begin{array}{c}\text { Porcentaje } \\
\text { de reservorios } \\
\text { negativos a } \\
\text { AVL }\end{array}$ \\
\hline 6 & $\begin{array}{c}\text { Pozas naturales } \\
\text { (no cloradas) }\end{array}$ & 0.00 & 100.00 \\
\hline 14 & Piscinas cloradas & 14.28 & 85.72 \\
\hline 9 & $\begin{array}{c}\text { Piscinas naturales } \\
\text { (no cloradas) }\end{array}$ & 11,10 & 88.90 \\
\hline 1 & Lago & 0.00 & 100.00 \\
\hline
\end{tabular}

Tabla 3. Porcentaje de positividad al AVL en reservorios de aguas con fines recreativos.

\begin{tabular}{|c|c|c|}
\hline $\begin{array}{c}\text { Total de reservorios de } \\
\text { agua (pozas, piscinas y } \\
\text { lago) }\end{array}$ & Positivas a AVL & Negativas a AVL \\
\hline 30 & 3 & 27 \\
\hline $100 \%$ & $10 \%$ & $90 \%$ \\
\hline
\end{tabular}


Tabla 4. Porcentaje de positividad al AVL en reservorios de aguas encontrados en los departamentos estudiados.

\begin{tabular}{|c|c|c|c||}
\hline Departamento & $\begin{array}{c}\text { Núm. de } \\
\text { reservorios de } \\
\text { agua estudiados }\end{array}$ & $\begin{array}{c}\text { Núm. de } \\
\text { reservorios de } \\
\text { agua positivos } \\
\text { a AVL }\end{array}$ & $\begin{array}{c}\text { Porcentaje } \\
\text { positividad a AVL } \\
\text { por Departamento }\end{array}$ \\
\hline La Libertad & 9 & 3 & $33 \%$ \\
\hline La Paz & 3 & 0 & 0 \\
\hline Santa Ana & 9 & 0 & 0 \\
\hline San Salvador & 5 & 0 & 0 \\
\hline San Vicente & 4 & 0 & 0 \\
\hline
\end{tabular}

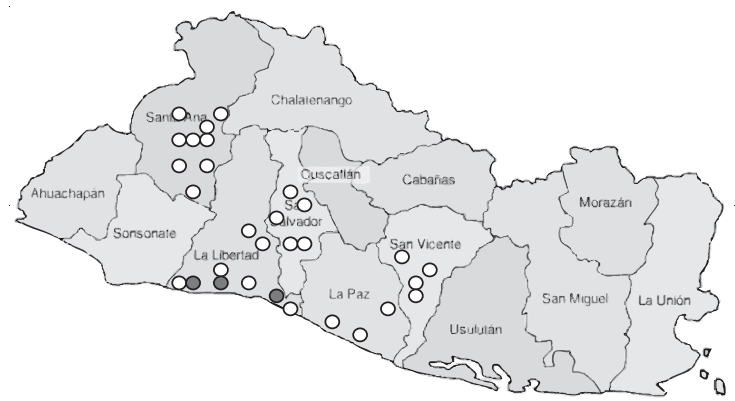

Figura 1. Mapa de ubicación de los reservorios de agua.

Muestras tomadas $O$ Muestras positivas a AVL $\mathrm{O}$

\section{DISCUSIÓN}

Este estudio mostró que hay presencia de AVL en algunos reservorios de agua, advirtiendo que dicha presencia es poca. Cabe señalar que la ubicación de las AVL fue únicamente en aguas profundas, posiblemente por la diversidad de factores que intervienen en su biología, y que condicionan su lugar de hábitat. Algunos de estos factores son: tipo de recirculación del agua, material utilizado para la construcción de la piscina y tiempo de uso, frecuencia con que acuden los bañistas y acúmulo de substancias orgánicas de diversos orígenes. No se tiene una clara explicación para el hecho de encontrar, aunque mínimo, un mayor porcentaje de presencia de AVL en aguas previamente cloradas que en aguas no cloradas. Sin embargo, debe indicarse que en la literatura se menciona que los agentes desinfectantes como el cloro son eficaces para disminuir la población bacteriana y micotica, pero no existe una definición inequivoca sobre el efecto que dichos agentes producen en la población amibiana, y otros protozoarios.

\section{CONCLUSIONES}

De este estudio se puede afirmar lo siguiente:

1. Se encontró presencia de AVL en tres de treinta reservorios estudiados

2. La presencia de $A V L$ en el agua de reservorios para uso recreativo de la población, no fue generalizada en el país, sino únicamente en el departamento de La Libertad.

3. La cloración de las aguas de balnearios, no es garantía absoluta para eliminar la presencia de AVL.

\section{RECOMENDACIONES}

Entre las recomendaciones sugeridas a partir de la investigación, están las siguientes:

1. Sugerir a los diferentes centros de estudio e investigación, la realización de trabajos similares al presente a fin de determinar, el género y la especie de las AVL que se encuentren. Esto permitirá establecer si las AVL detectadas, tienen correspondencia con aquellas que otros autores, en diferentes países, han encontrado y las han relacionado con patologías como la meningoencefalitis y úlceras de la córnea.

2. Se recomienda a las autoridades del Ministerio de Salud Pública y Asistencia Social, elaborar y difundir entre la población, las medidas de prevención del caso, para personas que utilizan diferentes reservorios de agua como diversión y esparcimiento.

3. Adicionalmente la información que arriba se menciona contribuiría a optimizar el conocimiento de las patologías ocasionadas por AVL, su diagnóstico, tratamiento oportuno y prevención para las personas que hacen uso de estos reservorios.

\section{AGRADECIMIENTOS}

A las autoridades de la Universidad Evangélica de El Salvador, por su apoyo incondicional para 
llevar a cabo este estudio. A las autoridades de cada lugar de donde se recolectaron las muestras de agua. Al Dr. Efraín Mena, por la asesoría técnica brindada, y a la Dra. Elizabeth Pérez, por su importante apoyo, durante el proceso de investigación.

\section{REFERENCIAS}

1. Botero, D. y Restrepo, M. Parasitosis Humanas. $3^{\circ}$ ed. Colombia. Corporaciones biológicas. Cl.B.1998.

2. Cubero Menéndez, O. y Cubero Rego, D. Meningoencefalitis amebiana primaria. Reporte de un caso. V Congreso Virtual Hispanoamericano de anatomía Patólogica.UNINET.2002.

3. Callegos Neyra, EM. Las peligrosas amebas. Investigación y desarrollo. Universidad Nacional Autónoma de México 2002.

4. Schuster F, Visvesvara G. Free-living amoebae as opportunistic and non-opportunistic pathogens of humans and animals. Int J Parasitol;34:1001-27.2004.

5. Beltrán de Estrada, M. Y Uyema, TN. Amebas de vida libre en muestras de agua de piscinas del departamento de Lima. Rev. Perú. Med. Exp. Salud Pública. Ene/jul, vol.14, No.1, p.29-33. ISSN 1726-4634.1997.

6. Astorga Leiva, B. Amebas de vida libre. Diagnóstico de Acanthamoeba sp. En pacientes con queratitis. Instituto de salud público de Chile.2001.

7. Suárez, R. Espinoza, Y., Villanueva, C., Ramos, J., Huapaya, P., Marquina, R. Aislamiento de amebas de vida libre del género Acanthamoeba a partir de fuentes de agua en la ciudad de lca. Anales de la Facultad de Medicina. Universidad Nacional de Mayor de San Marcos.2002.

8. Suarez, R., Olaya, P., Huapaya Herreros Herreros, P., Miranda, E., Náquira Velarde, C. Aislamiento de Acanthamoeba en pacientes del servicio de oftalmología de Hospital Nacional Cayetano Heredia. An. Fac. Med. (Perú); 63(4) 269274.2002

9. Jiménez Cardoso, E., Wong Cavaría, H., Rentería Carcía, H. Aislamiento de Acanthamoeba en lentes de contacto, estuches y soluciones preservadores de usuarios del departamento de lentes de contacto del hospital oftalmológico de Nuestra Señora de la Luz. Rev. Mex. Oftalmol. Kiderlen, AF, Laube, U. Balamuthia mandrillaris, an opportunistic agent of granulomatous amebic encephalitis, infects the brain via the olfactory nerve pathway. Parasitol Res; 94-52.2004.

10. Narván Soto, Joaquin. Encefalitis amebiana primaria granulomatosa. Diagnostico (Peru); 35(2): 13-19.1996.

11. Visvesvara CS, Balamuth W. Comparative studies on related free-living an pathogenic amebae with special reference to Acanthamoeba J. protozool; 22: 245-56.1975.

12. Primary amebic meningoencephalitis. North Carolina, MMWR; 41(25): 437 - 440.1992.

13. Muñoz, V., Reyes, H., Toche, P. Cárcamo, CY Cottlieb, B. Aislamiento de amebas de vida libre en piscinas públicas de Santigo de Chile. Parasitol. Latinoam. 58; 106-111.2003.
14. Visvesvara CS, Stehr-Green JK. Epidemiology of free-living ameb infections. J protozool. jul - aug; 37 255-335.1994.

15. Casero, R.D. Amebas patógenas de vida libre. Infect. Microbiol. Clin; 6(4): 107-13.1994.

16. Barrio, B., Pereda Soriano. M., Minués Muro, E., Cristóbal Bescós, J. A., Clavela Romano, OP. Ortoqueratología y Queratitis por Acanthamoeba. Revista Española de Contactología . Tomo IX (1); 342-354.1999.

17. Blatapie, L, Cremona, C., Carrasco, MA, Molina, V.E., Bozzini, JP. y Mariano, ML. Queratitis inflamatoria por Acanthamoeba spp. Análisis estructural por microscopia electronica de transmisión. Parasitolo. Latinoam. 58; 159-165.2003.

18. Ettinger, MR. webb, S.A., Melninch, S.P., C Garman, $G$ and Brown, BL. Distribution of free-living amoebae in James River Virginia. USA. Parasitol Res. 89(1): 6-15.2003.

19. Galarza, Carlos, Cutierrez, Ericson, Uribe, Martha et al. Amebas de vida libre en lesiones cutáneas: Reporte de 4 casos. Dermatol. Perú., ene/abr. vol. 16, No.1, p. 36-40. ISSN 1028-7175.2006.

20. Celman B, Raufs, Nader R, Popov V, Bokowski J, Chaljub C, Nauta H. Amoebic encephalitis due to Sappinia diploidea. Jam Med Assoc. 285: 2450-51.2001.

21. Gottlieb B. Meningoencephalitis amebiana primaria. Cap 33, en parasitología clínica de Atias - Neghme, tercera edición Mediterráneo Ltda.. Santiago de Chile 1991.

22. Gualdo Neves, MC., Bonasse, J., Wilson Castro, E.Encefalitis amebiana granulomatosa en una paciente no inmunocomprometida. Arch. Med. Interna (Montevideo); 18(4): 171-4.1996.

23. Intalapaporn, P., Suan Kratay, C., Shuangshoti, S., Phantumchianda, K., Keelawat, S., Wilde, H. Balamuthia mandrillaris meningoencephalitis: the first case in southeast Asia. Am. I. Trop. Med. Hyg; 70(6): 666-9.2004.

24. Reyes, E., Herrera, M., Alvarado, QFB., et al. (1997). Infección por amebas de vida libre. Reporte de un caso. Rev: Hosp... Jua. Mex 64(4). 68-69. Primary amebic meningoencephalitis. Ceorgia . MMWR. 52(40); 692-964.2003.

25. Se M. Human pathology caused by free-living amoebae. Ann lst Super Sanita. 33: 551-66.1997.

26. Schuster, FL. Cultivation of pathogenic and opportunistic free-living amebas. Clinical Microbiology Reviews. 15(3); 342-354.2002

27. Uribarren, Berrueta. Naegleriotosis, Acanthamoebosis, Balamuthiosis. Depto. de Microbiología y Parasitología. Fac. Med. UNAM, México DF.2004.

Figura:

1. Disponible en: wwwviajejet.com Directorio: URL:http//mapade-el-salvador/mapa-san-salvador-y-sus-departamentos consultado el 2 de abril de 2010. 